\title{
Manakins can produce iridescent and bright feather colours without melanosomes
}

\author{
Branislav Igic*, T, Liliana D’Alba ${ }^{\ddagger}$ and Matthew D. Shawkey ${ }^{\ddagger}$
}

\begin{abstract}
Males of many species often use colourful and conspicuous ornaments to attract females. Among these, male manakins (family: Pipridae) provide classic examples of sexual selection favouring the evolution of bright and colourful plumage coloration. The highly iridescent feather colours of birds are most commonly produced by the periodic arrangement of melanin-containing organelles (melanosomes) within barbules. Melanin increases the saturation of iridescent colours seen from optimal viewing angles by absorbing back-scattered light; however, this may reduce the wide-angle brightness of these signals, contributing to a dark background appearance. We examined the nanostructure of four manakin species (Lepidothrix isidorei, L. iris, L. nattereri and L. coeruleocapilla) to identify how they produce their bright plumage colours. Feather barbs of all four species were characterized by dense and fibrous internal spongy matrices that likely increase scattering of light within the barb. The iridescent, yet pale or whitish colours of $L$. iris and $L$. nattereri feathers were produced not by periodically arranged melanosomes within barbules, but by periodic matrices of air and $\beta$-keratin within barbs. Lepidothrix iris crown feathers were able to produce a dazzling display of colours with small shifts in viewing geometry, likely because of a periodic nanostructure, a flattened barb morphology and disorder at a microstructural level. We hypothesize that iridescent plumage ornaments of male $L$. iris and $L$. nattereri are under selection to increase brightness or luminance across wide viewing angles, which may potentially increase their detectability by females during dynamic and fast-paced courtship displays in dim light environments.
\end{abstract}

KEY WORDS: Animal coloration, Inverse opal, Iridescence, Lepidothrix, Manakin, Brilliant white

\section{INTRODUCTION}

Coloration has diverse functions and can communicate information such as an individual's quality, aggression level, genetic make-up or toxicity (Ruxton et al., 2004; Pryke and Griffith, 2009; Shi et al., 2015; Young et al., 2016). Sexual selection is the primary evolutionary driver of ornamentation among animals, and has produced some of the most extraordinary colours in nature (Kirkpatrick and Ryan, 1991; Price et al., 1993; Andersson, 1994). Evolution of conspicuous and elaborate colour patterns is often driven by mate choice or intra-sexual competition for mates

Department of Biology, The University of Akron, Akron, OH 44325, USA.

*Division of Evolution, Ecology \& Genetics, Research School of Biology, Australian National University, Canberra 2601, Australia. ${ }^{\ddagger}$ Present address: Department of Biology, Terrestrial Ecology Unit, Ledeganckstraat 35, Gent 9000, Belgium.

${ }^{\top}$ Author for correspondence (brani.igic@gmail.com)

B. B., 0000-0002-3219-6381

Received 8 January 2016; Accepted 23 March 2016
(Doucet et al., 2007; Chen et al., 2012), but also aposematic and warning communication (Ruxton et al., 2004; Kraemer et al., 2015). Indeed, males of diverse taxa, including spiders, birds, fishes, reptiles and mammals, use colourful traits to attract females (Kodric-Brown, 1985; Setchell and Jean Wickings, 2005; StuartFox and Moussalli, 2008; Girard and Endler, 2014). Sexual selection often favours conspicuous colours, which can be achieved by maximizing their chromatic or achromatic contrast against the environment or other body regions (Endler, 1992; Uy and Endler, 2004; Doucet et al., 2007).

Coloration of animals is produced by pigments, nanostructures or a combination of both pigments and nanostructures (Shawkey and Hill, 2006; Bagnara et al., 2007; Kinoshita, 2008; Stavenga et al., 2011b; D'Alba et al., 2012; Saba et al., 2014; Wilts et al., 2015). Pigments produce colour by selectively absorbing specific wavelengths of visible light while allowing others to be reflected. By contrast, structural colours are produced by periodic nanostructures that interfere with light within visible wavelengths and cause particular wavelengths to be amplified or attenuated through constructive and destructive interference, respectively (Vukusic and Sambles, 2003; Kinoshita, 2008). Unlike pigments, structural colours are capable of producing colours that change with viewing geometry (iridescence; Osorio and Ham, 2002; Kinoshita, 2008; Doucet and Meadows, 2009). Iridescence is a common and important component of avian courtship displays (Hill, 2006), and males of many species use dazzling displays of changing colours to impress or capture the attention of females (e.g. Parotia lawesii and Pavo cristatus; Stavenga et al., 2011a; Dakin and Montgomerie, 2013). Although not traditionally defined as a colour, white is a common and important component of animal coloration; it is produced by the diffuse and wavelength-independent scattering of light by disordered nanostructures (Dyck, 1979; Vukusic et al., 2007) and is involved in the perception of luminance or brightness of colour signals.

The highly iridescent plumage coloration of birds described so far requires the presence and nanoscale arrangement of melanosomes (melanin-containing organelles) to produce visible colour changes. Although melanins are pigments that absorb light across all wavelengths visible to birds (300-700 nm; Osorio and Vorobyev, 2005; Meng and Kaxiras, 2008), for many birds, the precise arrangement of melanosomes within their feather barbules produces iridescent colours by causing particular reflected wavelengths to be amplified, while others are attenuated, as light travels through materials that periodically vary in refractive index (i.e. air, $\beta$-keratin and melanin; Greenewalt et al., 1960; Stavenga et al., 2011a; Maia et al., 2011; Eliason et al., 2013). Independent of the nanoscale arrangement of melanosomes, some species produce weakly iridescent colours through quasi-ordered nanostructures of $\beta$-keratin and air within feather barbs (Noh et al., 2010a). However, these nanostructures require a basal layer of melanosomes to produce visible colour (Shawkey and Hill, 2006) and their 
iridescence is not visible under natural light conditions (Osorio and Ham, 2002; Noh et al., 2010a). Although the $\beta$-keratin cortex of feather barbs can produce weak iridescence through thin-film interference without the contribution of melanosomes, this effect is only dominant at micro-scales and likely contributes minimally to the coloration seen at visually relevant spatial scales (Stavenga et al., 2011b)

Directional reflection of colour is a common property of many strongly iridescent feathers. For example, the spectacular iridescent patches of many species [e.g. hummingbirds, the ribbon-tailed astrapia (Astrapia mayeri) and the magnificent riflebird (Ptiloris magnificus)] reflect bright, saturated and iridescent colours in specific directions (often in specular or mirror-like directions), while appearing dark or cryptic at other angles (Osorio and Ham, 2002; Doucet and Meadows, 2009). This directional reflection of colour is due to planar morphologies of colour-producing barbules that reflect light in specific directions (e.g. the flat or boomerang-shaped barbules of P. lawesii; Stavenga et al., 2011a, 2015). By contrast, a curved barbule morphology reduces both the magnitude of colour change and the angle dependence of iridescent feather colours, so that colour can be seen from a wider range of viewing angles (Dyck, 1987; Yoshioka and Kinoshita, 2002). Melanosomes also likely play an important role in increasing the directionality of highly iridescent feathers. By absorbing light that is diffusely scattered or reflected, melanosomes increase the saturation of iridescent feather colours (Yoshioka and Kinoshita, 2002; Xiao et al., 2015) and contribute to their dark background appearance, as suggested by Brink and Van Der Berg (2004). In turn, this may explain the rarity of iridescent feathers with a pale background appearance (similar to coloration of white opals).

Male manakins (Pipridae) use some of the brightest plumage colours among birds to attract females (Kirwan and Green, 2011). Manakins comprise a diverse clade of small frugivorous birds that contains 42-57 species (depending on taxonomic classification) distributed across the Neotropics (Prum, 1990; Rêgo et al., 2007; Ohlson et al., 2013). Males of most species court females within leks using elaborate colours, strange and unique sounds, and stereotyped movements (Prum, 1990, 1998; Endler and Thery, 1996; Durães, 2009; Kirwan and Green, 2011; Lukianchuk and Doucet, 2014). Males in the genus Lepidothrix display bright colours on their crown and rump feathers (Fig. 1), such as brilliant whites, vibrant blues, golds and iridescent opal-like colours (Kirwan and Green, 2011; present study). Despite considerable interest in the function and evolution of coloration within this family of birds (Endler and Thery, 1996; Doucet et al., 2007; Ribeiro et al., 2015), characterization of their coloration and examinations of colour production mechanisms have primarily focused on noniridescent blues and greens (Saranathan et al., 2012). Here, we examined and compared the coloration and colour production mechanisms across plumage ornaments of four Lepidothrix species, primarily focusing on two species with iridescent plumage but, unusually, with white or pale-coloured background appearances.

\section{MATERIALS AND METHODS}

We examined the crown and rump feather colours of four different Lepidothrix manakins (Fig. 1): brilliant white crown feathers of the blue-rumped manakin [L. isidorei (Sclater 1852)]; opalescent crown feathers of the opal-crowned manakin [L. iris (Schinz 1851)]; pinkish-white rump feathers of the snow-capped manakin [L. nattereri (Sclater 1865)]; and blue rump feathers of the
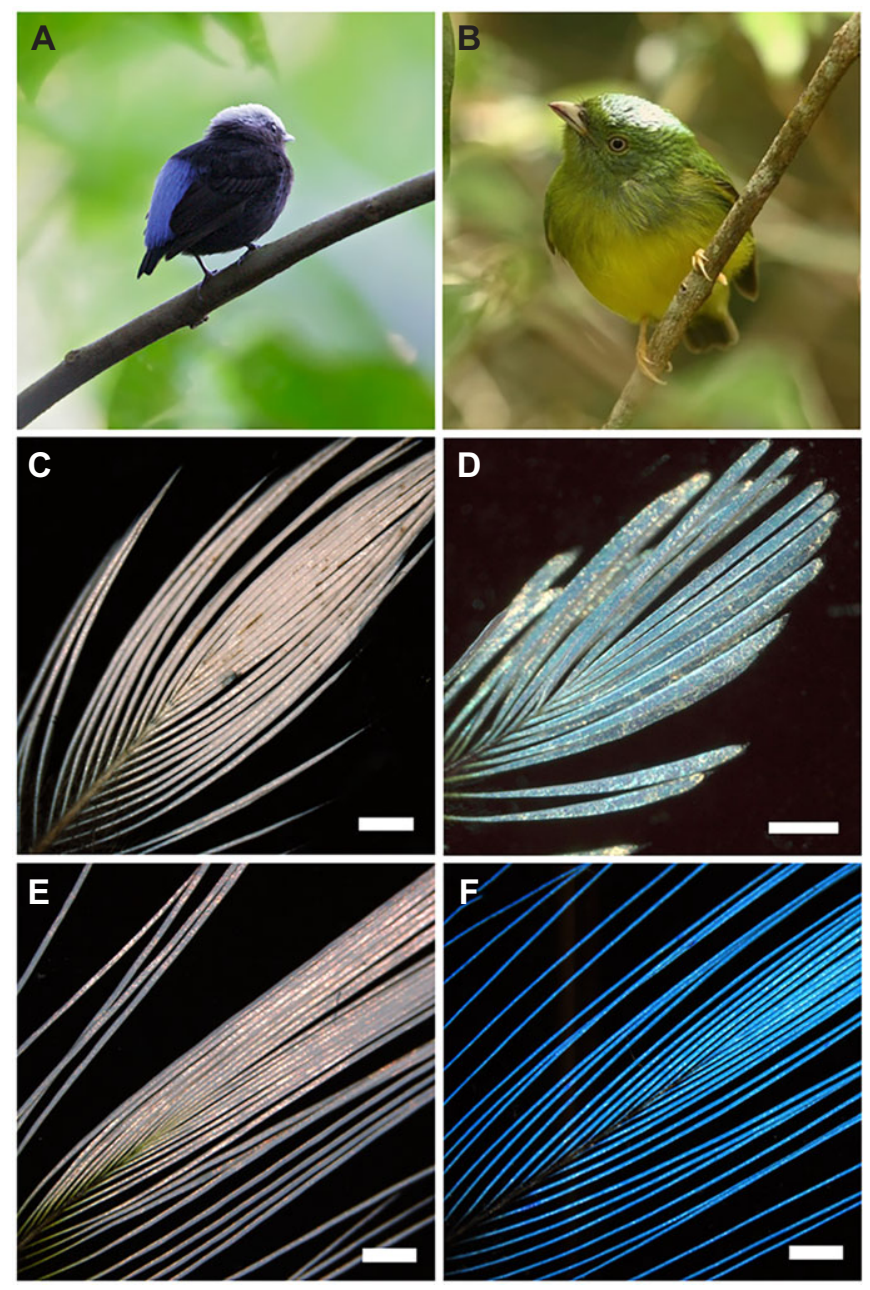

Fig. 1. Study species and feathers. Photographs of $(A)$ Lepidothrix isidorei (photo credit: Ben Sadd) and (B) L. iris (photo credit: Marcelo Barreiros), as well as (C) L. isidorei crown, (D) L. iris crown, (E) L. nattereri rump and (F) L. coeruleocapilla rump feathers. Scale bars, $0.5 \mathrm{~mm}(\mathrm{C}-\mathrm{F})$.

cerulean-capped manakin [L. coeruleocapilla (Tschudi 1844)]. All feathers were kindly provided by the Field Museum of Natural History (Chicago, IL, USA).

\section{Reflectance measurements}

We measured specular and diffuse spectral reflectance of feathers between 300 and $700 \mathrm{~nm}$. For each measurement, we flattened single feathers by taping their calamus to low reflective black velvet fabric and oriented the feathers such that the incident light beam hit the pennacous barbs at a proximal to distal orientation. We measured specular reflectance between 10 and $50 \mathrm{deg}$ from coincident normal at $5 \mathrm{deg}$ increments at two different locations per feather using a spectrometer equipped with two fibres that rotate independently from one another (Igic et al., 2015); one fibre was connected to a light source (AvaLight-XE pulsed xenon light, Avantes, Broomfield, CO, USA) and the other fibre was connected to a spectrometer (AvaSpec-2048 spectrometer). We measured specular reflectance at coincident normal and back-scattering at 45 deg using a bifurcated probe and a block holder (AFH-15, Avantes), and measured diffuse reflectance collectively across all possible angles at three different locations per feather using an integrating sphere with a black gloss trap to exclude specular reflectance (AvaSphere-50-REFL). To examine the scattering 
processes responsible for producing the different reflectance peaks, we used Glan-Thompson linear polarizers (Harrick Scientific Products, Pleasantville, NY, USA) to identify whether reflected light was either parallel (co-polarization) or perpendicular (cross-polarization) to polarized incident light (Noh et al., 2010a,b). Using this experimental setup, reflected light that is scattered only once will maintain co-polarization, whereas a double scattering process would cause reflected light to be both co- and cross-polarized (Noh et al., 2010a,b). All reflectance measurements were taken relative to a diffuse white standard (WS-2, Avantes).

\section{Examination of feather structure}

To identify the mechanisms of colour production, we examined the structure of whole feathers and feather barbs using light, scanning electron and transmission electron microscopes. We primarily focused our attention on the structure of barbs, rather than barbules, because barbules were either absent from colourproducing regions or greatly reduced in size and fused to the underside of barbs (Fig. 1; see Results). For light microscopy, we used a Leica S8AP0 (Leica Microsystems, Wetzlar, Germany) equipped with a MicroPublisher 5.0 RTV FireWire camera (Q Imaging, Surrey, BC, Canada). To prepare samples for scanning electron microscopy (SEM), we fragmented barbs using a scalpel and mounted them onto aluminium stubs to allow visualisation of cross-sections, which we then coated with gold/palladium for $3 \mathrm{~min}$. The estimated sputter coat thickness was $12 \mathrm{~nm}$ based on a plasma discharge of $18 \mathrm{~mA}$, voltage of $1.8 \mathrm{keV}$ and a 1.2 constant for $\mathrm{Au} / \mathrm{Pd}$ in argon (Echlin, 2011). We also mounted $1 \mu \mathrm{m}$ thick cross-sections and transverse sections of the barbs (embedded in Epon and sectioned using the protocol described below) to allow SEM visualisation of nanostructure across a flatter plane. We imaged barb sections using a JSM-7401F SEM (JEOL, Tokyo, Japan), at a working distance of $7 \mathrm{~mm}$, and an accelerating voltage of $7 \mathrm{kV}$. To prepare samples for transmission electron microscopy (TEM), we first washed fragmented barbs in $100 \%$ ethanol for 20 min twice, and then immersed the washed fragments in successive concentrations of 15, 50, 70 and $100 \%$ Epon (diluted using 100\% ethanol) for $24 \mathrm{~h}$ (Shawkey et al., 2003). Barbs were then placed in moulds to allow sectioning of both cross-sections and transverse sections, and were cured in an incubator for $24 \mathrm{~h}$ at $60^{\circ} \mathrm{C}$. We cut $100 \mathrm{~nm}$ thick sections using an Ultra 45 diamond knife (Diatome, Biel, Switzerland) on a Leica EM UC6 ultramicrotome (Leica Microsystems), which we placed on 200 mesh, formvar-coated copper grids (Electron Microscopy Sciences, Hatfield, PA, USA) and imaged using a JEOL JEM-1230 TEM operating at $120 \mathrm{kV}$. We examined the spatial ordering of the barb nanostructure using the fast Fourier transform (FFT) tool in ImageJ (http://imagej.nih.gov/ij/). We acknowledge the limitations of using TEM images and 2D FFT to test assumptions about the 3D structures of biological nanostructures (Shawkey et al., 2009; Saranathan et al., 2012), and therefore use this only as an exploratory tool to examine the potential for nanostructural periodicity.

\section{Optical modelling}

The internal nanostructures of $L$. iris and $L$. nattereri barbs resembled those of hexagonally packed inverse opals. Therefore, we used a modified equation based on Bragg's and Snell's laws to estimate the peak wavelength of reflectance produced by a closepacked hexagonal nanostructure (Aguirre et al., 2010):

$$
\lambda_{\max }=1.633 D \sqrt{n_{\mathrm{eff}}^{2}-\sin ^{2} \theta},
$$

where $\lambda_{\max }$ is the wavelength with maximum reflectance, $D$ is the average void spacing, $n_{\text {eff }}$ is the effective refractive index of the material and $\theta$ is the angle of specular reflection. For $D$, we used the average distance between void centroids (mean \pm s.e.m., $257 \pm 3.9$ and $307 \pm 3.9 \mathrm{~nm}$ for $L$. iris and L. nattereri, respectively), which we measured as an average nearest neighbour distance between centroids of 58-69 voids on TEM images (149-162 individual nearest neighbour distances). The effective refractive index can be calculated using:

$$
n_{\text {eff }}=\phi n_{\mathrm{voids}}+(1-\phi) n_{\mathrm{walls}},
$$

where $\phi$ is the solid fraction of the material, and $n_{\text {voids }}$ and $n_{\text {walls }}$ are the respective refractive indices of the spherical voids and the solid walls of the material. We estimated $\phi$ using the binary function of Image J to calculate the relative proportions of walls relative to voids on a section of the barb on TEM images. Excluding the cortex and the cell vacuoles, the solid walls contributed to approximately $72 \%$ of the barbs' internal structure for both L. iris and L. nattereri. For the refractive indices of the voids and the solid walls, we respectively used the refractive index of air $(n=1)$ and $\beta$-keratin ( $n=1.56$; Stavenga et al., 2015). Although this simple theory can estimate the wavelength of peak reflectance of isotropic hexagonally close-packed nanostructures, it cannot be used to estimate any other spectral characteristics of materials and cannot take into account the curvature and cortex thickness of barbs, nor the variability in the nanostructure (Table 1), all of which could affect the spectral properties of these feathers.

In addition to the equations for a hexagonally close-packed structure, we used optical equations published in Xiao et al. (2014) to test how well the predictions of 1D multilayer structure fit the measured spectra for L. iris and L. nattereri. Given their organised 3D structure, a 1D multilayer model was unlikely to explain the reflectance properties of these feathers. However, we see value in presenting these predictions to provide comparison with those

\begin{tabular}{|c|c|c|c|c|c|c|}
\hline Species & Colour & Iridescent & $\begin{array}{l}\text { Average barb } \\
\text { cortex thickness }(\mathrm{nm})\end{array}$ & $\%$ Air vacuole & $\begin{array}{l}\text { Average diameter of } \\
\text { air voids [nm] (CV) }\end{array}$ & $\begin{array}{l}\text { Average aspect ratio } \\
\text { of air voids }(\mathrm{CV})\end{array}$ \\
\hline L. isidorei & White & No & 930 & 24.3 & $320(12.8)$ & $1.2(12.4)$ \\
\hline L. nattereri & Pinkish white & Yes & 740 & 33.9 & $287(9.3)$ & $1.2(9.3)$ \\
\hline L. coeruleocapilla & Blue & $Y_{e s}^{a}$ & 493 & 23.3 & $157(16.7)$ & $1.5(17.4)$ \\
\hline L. iris & Opalescent & Yes & 518 & 32.6 & $252(11.7)$ & $1.2(12.4)$ \\
\hline
\end{tabular}

Table 1. Summary of colour and barb morphology of feathers from four Lepidothrix manakin species

$\%$ Air vacuole is measured as the percentage of barb cross-section area composed of air vacuoles; air void diameter is measured as the average diameter along the major and minor axes of 120 individual voids on TEM images; aspect ratio is measured as the ratio of minor to major axis diameters of 120 individual voids on TEM images. CV, coefficient of variation (\%)

aridescent under uni-directional light, but potentially not under omni-directional light (Noh et al., 2010a). 
produced by the equations for hexagonally close-packed structures. Our 1D multilayer calculations were based on cortex thicknesses of 518 and $740 \mathrm{~nm}$ (Table 1); air layer thicknesses of 146 and $250 \mathrm{~nm}$; keratin layer thicknesses of 104 and $98 \mathrm{~nm}$ (all respectively for L. iris and L. nattereri); 15 layer stacks, which was the approximate number of keratin/air layers between the edge and centre of medullary cells; volume fractions of $72 \%$ for the air layer; and the above specified refractive indices for air and $\beta$-keratin.

\section{RESULTS}

Almost all the manakin feathers examined here displayed angledependent specular coloration and broad diffuse reflectance (Fig. 2, Fig. S1). Lepidothrix iris crown feathers and $L$. nattereri rump feathers appeared iridescent to the human eye (Fig. 1, Movie 1). Their spectra showed peaks that shifted to narrower wavelengths with increasing angles of specular reflection (Fig. 3), and uniform reflectance across integrated diffuse angles (Fig. S1). By contrast, L. isidorei crown feathers had broad reflectance at both specular and diffuse geometries, and the L. coeruleocapilla rump feathers had blue and UV peaks in both specular and diffuse reflectance geometries (Fig. 2, Fig. S1). Both the L. iris crown feathers and the L. nattereri rump feathers had secondary peaks at shorter wavelengths, which, unlike their primary peaks, lost their polarization (peaks were present in both co- and cross-polarization), suggesting that they were produced by either higher-order scattering or diffraction (Figs S2, S3) (Noh et al., 2010b). The L. iris crown feathers displayed dramatic colour changes with subtle changes in viewing geometry (Movie 1). They appeared yellowish-green at specular geometries (peak reflectance changed from 599 to $499 \mathrm{~nm}$ with increases in specular angle), and appeared blue (peak reflectance: $420 \mathrm{~nm}$ ) or purple (peak reflectance: $600 \mathrm{~nm}$ for the primary peak and $367 \mathrm{~nm}$ for the secondary peak) at non-specular viewing geometries (e.g. blue when incident light and observation angles were at $45 \mathrm{deg}$ and surface normal, respectively; and purple when the feather was tilted at $50 \mathrm{deg}$ with incident light and observation angles at surface normal and $15 \mathrm{deg}$, respectively; Fig. 3, Fig. S2)

The bright coloration of these manakins' feathers was associated with dense internal barb nanostructures, absence or limited distribution of light-absorbing melanosomes, and a flattened barb morphology for L. iris feathers (Figs 4, 5, Fig. S4). The white barbs of $L$. isidorei and $L$. nattereri lacked barbules at their distal ends, whereas $L$. coeruleocapilla and $L$. iris barbs contained short, flat and melanised barbules at the distal ends (Figs 4, 5, Fig. S4). Barbs of all species comprised medullary cells, which contained central air-filled vacuoles and dense spongy networks of $\beta$-keratin at their exteriors, conforming to the sphere-type category for feather barb nanostructure (Fig. 5) (Prum, 2006; Saranathan et al., 2012). The central air-filled vacuoles comprised a larger portion of $L$. isidore crown feather barbs compared with the other species examined here (Table 1). Lepidothrix isidorei and L. nattereri barbs lacked melanosomes, whereas $L$. iris feathers had a restricted distribution of melanosomes along one edge of their barbs (Figs 4, 5, Fig. S4). Lepidothrix coeruleocapilla feathers had a broad distribution of melanosomes within their barbs and barbules (Fig. 5, Fig. S4).

The degree of spatial ordering of their internal nanostructures (Fig. 5, Fig. S5) varied across the four manakin species. Lepidothrix iris barb nanostructures had a hexagonally packed structure characteristic of inverse opal materials, but lacked long-range
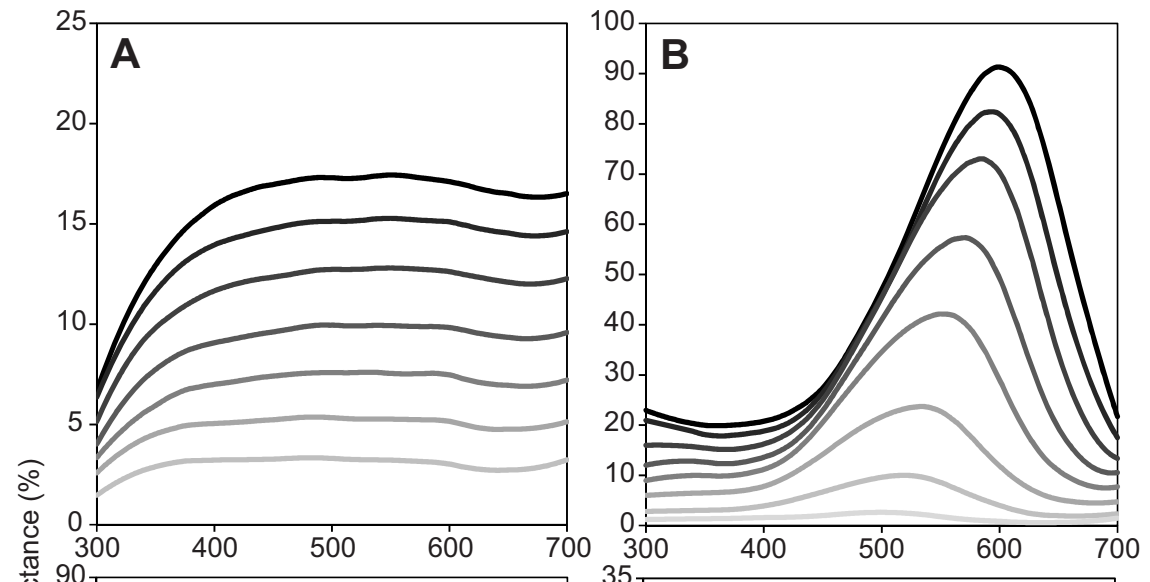

Fig. 2. Specular reflectance of individual feathers at 5 deg angle increments starting at $10 \mathrm{deg}$ (dark grey), and up to $\mathbf{5 0} \mathrm{deg}$ (light grey), from coincident normal (0 deg). (A) Lepidothrix isidorei crown, (B) L. iris crown, (C) L. nattereri rump and (D) L. coeruleocapilla rump feathers. Because of their small size, crown feathers could only be measured up to 45 deg from coincident normal. 


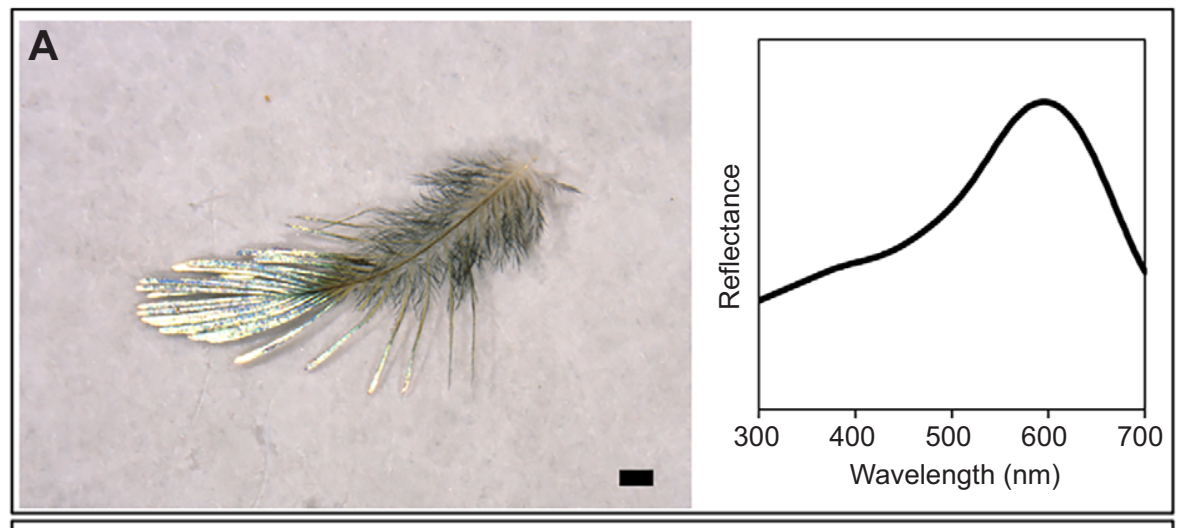

Fig. 3. Lepidothrix iris crown feathers at incident light at different viewing geometries. $(A, C)$ Normal incidence; $(B, D)$ both 30 and 45 deg from normal incidence; and $(E)$ in transmittance. Images show feathers either dorsal side up $(\mathrm{A}, \mathrm{B})$ or ventral side up $(C, D)$. Black regions seen in $C$ and $\mathrm{D}$ are melanised barbules and the narrow melanised region of the barb cortex. Scale bars, $0.5 \mathrm{~mm}(\mathrm{~A}, \mathrm{~B})$ and $0.1 \mathrm{~mm}(\mathrm{C}-\mathrm{E})$.
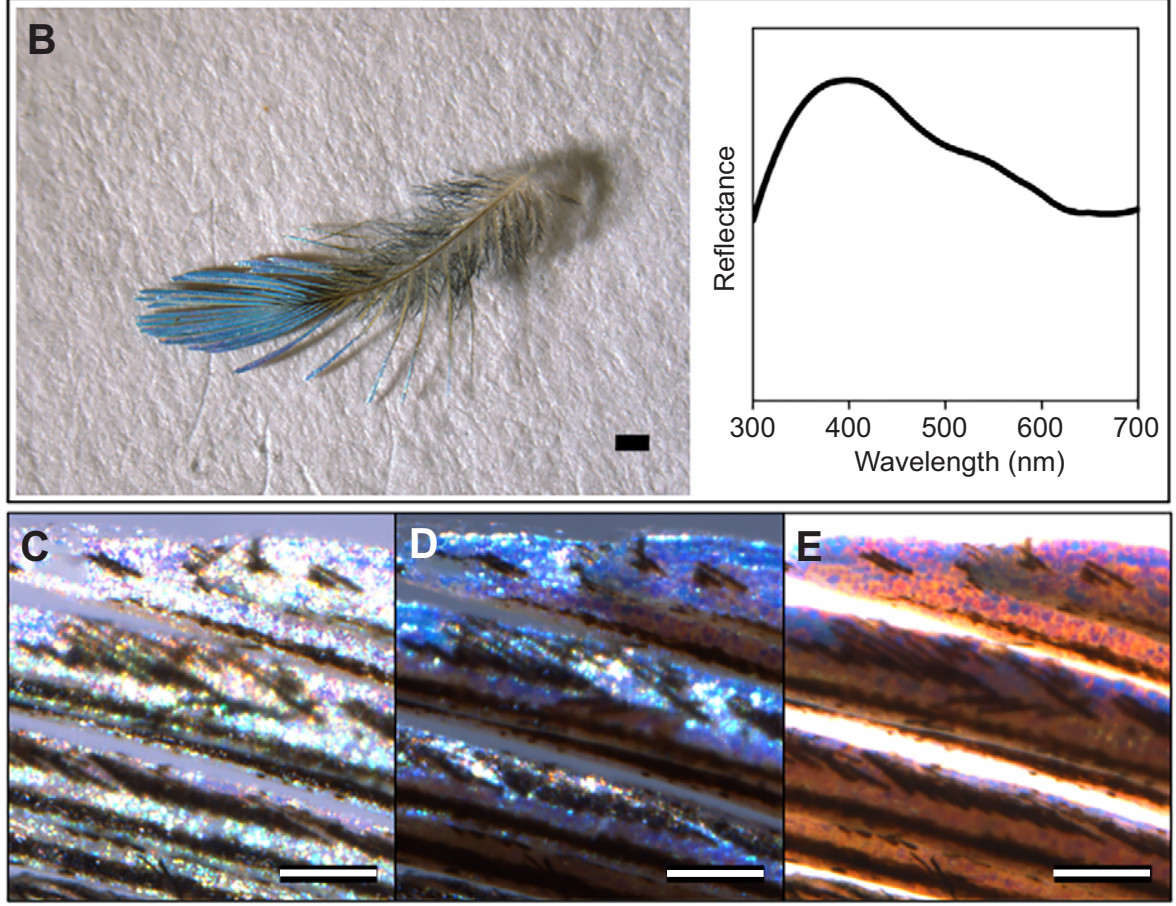

order (Fig. 5, Fig. S5). Lepidothrix nattereri and L. coeruleocapilla barbs had similar structures near their barb cortex but with lower spatial order relative to $L$. iris barbs (Fig. 5, Fig. S5). The L. isidorei barbs showed the least spatial ordering among the species examined (Fig. 5, Fig. S5). The diameter of voids differed across the four species, and none of the species had perfectly spherical or identically sized voids (Table 1), indicating that none of the feathers had an isotropic nanostructure. Despite their apparent absence of long-range order (Fig. S5), the peak reflectance predicted by optical calculations for 3D inverse-opal-like structures matched the measured peak reflectance for both $L$. iris and $L$. nattereri feathers, and better than optical calculations for a $1 \mathrm{D}$ multi-layer structure (Fig. 6). As could be predicted from their ordered 3D structure, a 1D multi-layer model was insufficient in explaining the spectral properties of these feathers (Fig. 6). The ellipsoid shapes and size variance of the air voids within their nanostructures (Table 1) likely resulted in the small discrepancies between their observed peak reflectance and that predicted using optical calculations for 3D inverse-opal structures (Fig. 6). Removing the barbules did not visibly affect the coloration of $L$. iris feathers, whereas crushing the barb structure caused their barbs to become translucent, confirming the structural origin of their coloration (Fig. S6).

\section{DISCUSSION}

The conspicuous and bright plumage colours of four Lepidothrix manakins were associated with dense and fibrous internal barb nanostructures. The four species studied here differed in overall barb shape, the degree of periodicity and distance between periodic structures within the barb's internal spongy $\beta$-keratin matrix, and the presence and distribution of melanosomes. The dense internal networks of $\beta$-keratin and air create many interfaces for light scattering, which in turn would increase the overall brightness (the total reflectance across all visible wavelengths) of diffusely reflected light (Dyck, 1979; Hanrahan and Krueger, 1993; Shawkey and Hill, 2005). The internal nanostructure of $L$. iris barbs is similar to barbs of several other species, including other manakins (present study; Saranathan et al., 2012), but is more periodic. This periodicity, in combination with a flat barb morphology and limited presence of melanosomes, produced highly directional and strongly iridescent coloration on a pale background for $L$. iris feathers.

Although we detected angle-dependent colour changes for three of the four manakin species, only L. iris crown feathers are clearly iridescent under natural light conditions. Structural blue colours produced by a quasi-ordered nanostructure, similar to that of L. coeruleocapilla rump feathers, can show iridescence under the directional light of a spectrometer, but not under natural light 


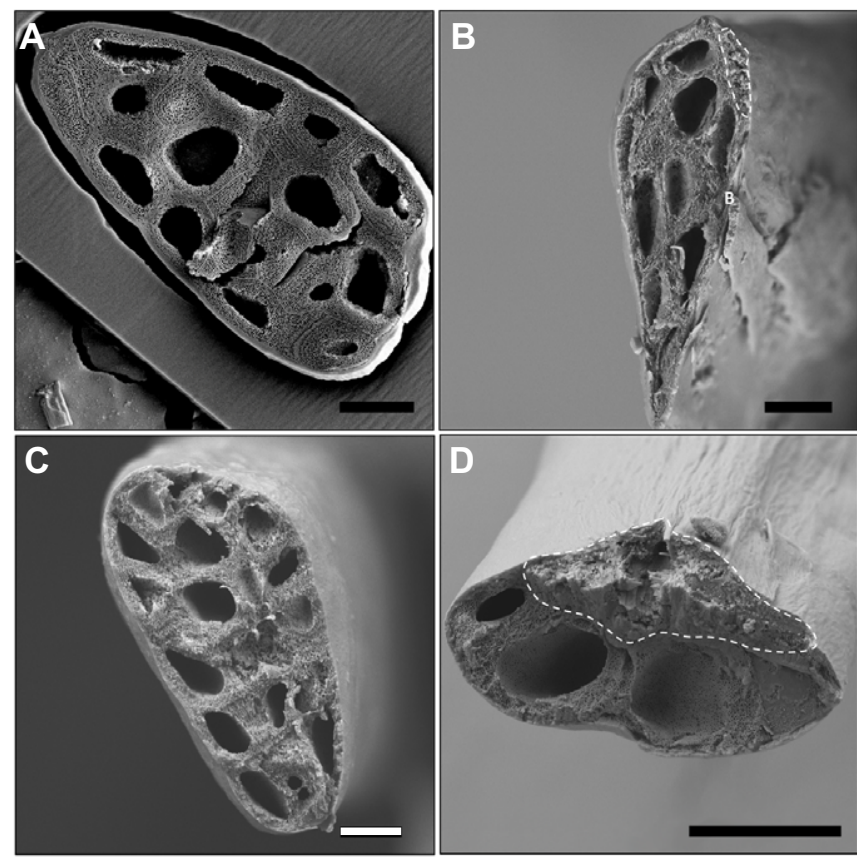

Fig. 4. SEM images of whole barb cross-sections. (A) Lepidothrix isidorei crown, (B) L. iris crown, (C) L. nattereri rump and (D) $L$. coeruleocapilla rump feathers. Melanised regions of barbs are indicated by dashed lines and the melanised barbule with 'B'. Scale bars, $10 \mu \mathrm{m}$.

conditions, because of the isotropic nature of the spongy matrix and the prevalence of back-scattered light (Osorio and Ham, 2002; Noh et al., 2010a). Although the periodicity of L. nattereri barbs was similar to that of $L$. coeruleocapilla, their reddish and iridescent highlights are seen by human vision at particular viewing angles, and therefore are possibly also visible to female manakins under natural light conditions. Interestingly, L. nattereri rump feathers have been described as brilliant white without reference to their iridescence (Kirwan and Green, 2011), suggesting that there may be geographic or sub-species variation in the degree or presence of the iridescent quality of their plumage. Alternatively, the absence of barbules to structure $L$. nattereri barbs into a uniform plane and a rounded barb morphology may reduce or mask the presence of these highlights when observing the plumage patches as a whole. Therefore, the presence of visible iridescence in this species requires further investigation using whole specimens. By contrast, the pure and brilliant white coloration of $L$. isidorei crown feathers is associated with a dense and disorganized internal nanostructure that likely causes wavelength-independent scattering of light to dominate (e.g. Vukusic et al., 2007).

The $L$. iris crown feathers produced diverse colours with small changes in viewing geometry independently of melanosome arrangement (Movie 1). To our knowledge, they provide the first reported example of feathers with highly directional iridescence produced independently of melanosomes or melanosome arrangement. The highly directional iridescence of other bird species' feathers studied to date is produced by the crystalline arrangement of melanosomes within barbules, which may be hollow or solid (Greenewalt et al., 1960; Stavenga et al., 2011a; Maia et al., 2011; Eliason et al., 2013). The L. iris crown feathers had a limited and ventral distribution of melanosomes that did not affect coloration when removed; their iridescent quality was produced by the periodic arrangement of air voids and $\beta$-keratin within the medullary layer of feather barbs. Similar inverse-opal
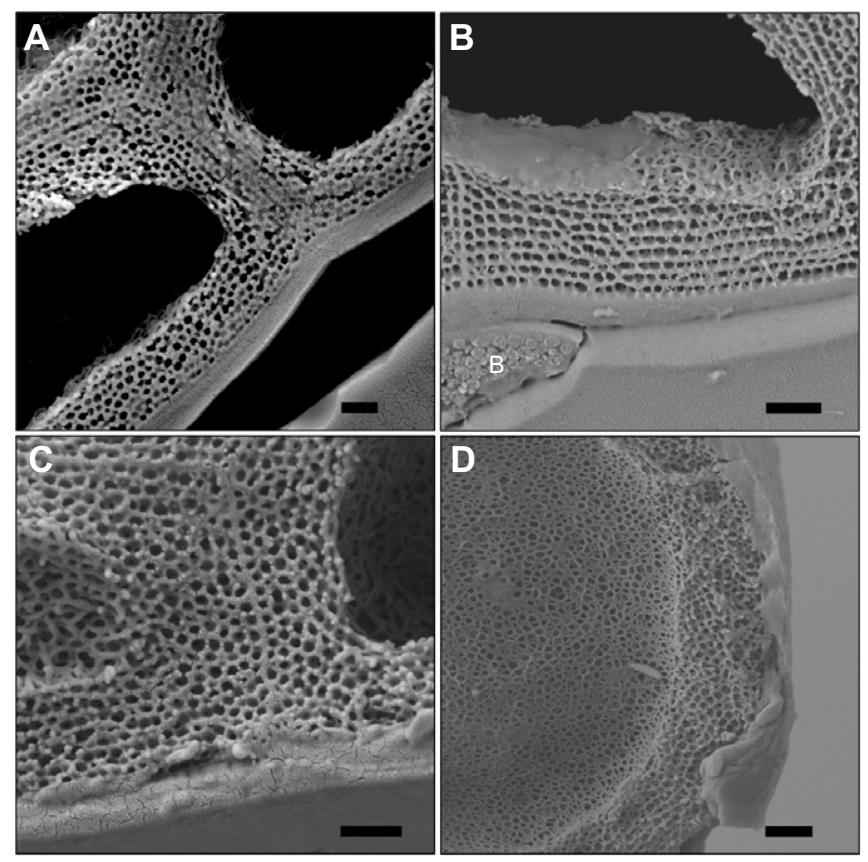

Fig. 5. SEM images of barb cross-sections at the junction of the cortex and medulla. (A) Lepidothrix isidorei crown, (B) L. iris crown, (C) L. nattereri rump and (D) $L$. coeruleocapilla rump feathers. Melanised barbule is indicated with 'B'. Scale bars, $1 \mu \mathrm{m}$.

structures have been shown to produce iridescent and opalescent colours in invertebrate taxa using air voids within a chitin matrix, most notably in butterflies and beetles (Welch and Vigneron, 2007; Seago et al., 2009). Depending on the angle of observation, L. iris crown feathers could appear white, yellowish-green, blue or purple. These angle-dependent colour changes were associated with a combination of short-range hexagonal nanostructural periodicity, a flattened barb shape, long-range disorder imposed by the presence of vacuoles at the centre medullary cells, and a restricted distribution of melanosomes. For example, diffraction of light by the periodically arranged air and $\beta$-keratin matrix likely produced the yellowish-green colour observed at specular geometry and was further enhanced by a flattened barb morphology. By contrast, blues and purples are perceived at non-specular angles, and therefore likely produced by higher-order diffraction (e.g. Eliason et al., 2013) or double scattering from a quasi-ordered nanostructure (e.g. Noh et al., 2010a). Light scatterometry, small-angle X-ray scattering and finite-difference time-domain modelling (Saranathan et al., 2012; Wilts et al., 2014) are necessary to further clarify the exact production mechanisms of colours observed at non-specular angles.

Producing iridescent colours without melanosomes potentially trades off richer angle-dependent colours for iridescent signals that appear brighter across a wider range of viewing angles. For example, including carbon black as a light-absorbing agent within structural coloured films composed of colourless colloidal particles increases their colour saturation through absorption of multiply scattered light; however, this occurs at the expense of reduced total reflectance over human visible wavelengths (Takeoka et al., 2013; Ohtsuka et al., 2015). The absence of melanosomes (and hence washing out of colour because of increased multiple scattering) may explain why the L. nattereri rump feathers appear pinkish, rather than the saturated structural reds produced using melanosomes (e.g. Greenewalt et al., 1960; Eliason et al., 2013; Xiao et al., 2014). Lepidothrix nattereri rump feathers may appear purple or pink, 

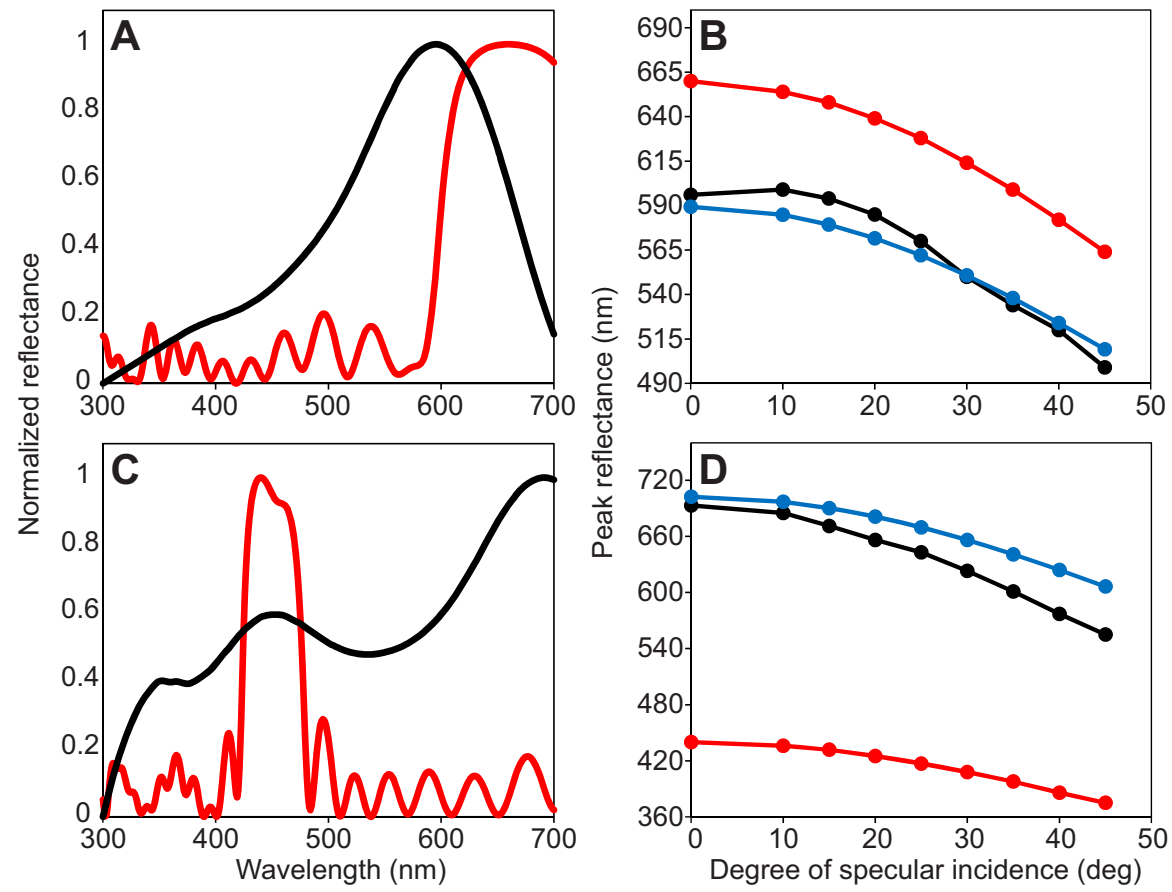

Fig. 6. Measured (black lines) and predicted spectral properties predicted using optical models for 3D inverse-opal photonic crystals (blue lines) or 1D multilayers (red lines). (A,B) Lepidothrix iris crown and $(C, D)$ L. nattereri rump feathers at normal incidence $(A, C)$ or across different specular angles $(B, D)$.

rather than red, if on a darker melanised background (Magkiriadou et al., 2014) because they lacked long-range order and had secondary peaks near blue wavelengths. Although L. iris barbs contained flat melanised barbules on their posterior side, and a restricted distribution of melanosomes within the barb cortex, the melanosomes appeared to contribute little to colour production as coloration persisted on unmelanised regions of barbs even after removal of the barbules. The limited posterior distribution of melanosomes on L. iris barbs may absorb some of the backscattered light and increase purity of colours to some extent (Shawkey and Hill, 2006; Zhang et al., 2015). The higher refractive index contrast between $\beta$-keratin and air (1.56 versus 1$)$, compared with that between $\beta$-keratin and melanosomes (1.56 versus 1.7; Leertouwer et al., 2011; Stavenga et al., 2015), may also increase the scattering of light within the nanostructure and contribute to a paler appearance; however, this hypothesis requires further investigation.

Our findings suggest that the plumage ornaments of some Lepidothrix manakins are under selection to maximize their brightness across all possible viewing geometries, resulting in production of iridescent colour signals with pale backgrounds. Increasing the total reflectance across all visible wavelengths (achromaticity) and viewing angles may increase the detectability of these traits by females as males fly around in dim forest light conditions and increase achromatic contrast with other body regions or with the environment (Marchetti, 1993; Doucet et al., 2007). Birds, like most animals, process achromatic and chromatic components of colour signals differently, and achromatic components are particularly important in detection of motion, form and patterns (Osorio and Vorobyev, 2005; Kemp et al., 2015), and therefore could be more important during the dynamic and fastpaced aspects of a male manakin's display. Although the courtship displays of the species examined here are not well described, their displays can involve extremely quick flights between several locations (https://www.youtube.com/watch?v=8XtIRcvbTbQ, accessed 21 March 2016). Intriguingly, the iridescent plumage patches of both $L$. iris and $L$. nattereri showed primary peaks at longer wavelengths, which may be particularly important in luminance perception (Osorio and Vorobyev, 2005). Similar highly directional, bright flashes of colours are important components of courtship displays in other bird species, such as in birds-of-paradise (family Paradisaeidae; e.g. Stavenga et al., 2011a; Wilts et al., 2014).

It is unclear why these types of pale opalescent colours are not more common among birds. Although several other species are described as having opalescent plumage (Tangara callophrys and $T$. velia; http://neotropical.birds.cornell.edu/portal/species/ identification?p_p_spp=611116; http://neotropical.birds.cornell. edu/portal/species/identification?p_p_spp $=610956$, accessed 21 March 2016), it is still unclear whether these species possess spectral properties or production mechanisms similar to those of the manakins described here. These ordered nanostructures within barbs may be physiologically more difficult to produce than melanosome-based iridescent colours within barbules. For example, the highly periodic arrangement of $\beta$-keratin and air may be difficult, if not impossible, to achieve through the passive selfassembly processes of phase separation that likely produce the quasi-ordered nanostructures of some feather barbs (Saranathan et al., 2012). Block copolymers, formed through linkage of polymerized monomers, readily phase separate into highly ordered nanostructures (Smart et al., 2008). Thus, perhaps keratin undergoes additional processing to form block copolymers during development in some manakin feathers; however, this is speculative and more work is needed to test these hypotheses. Furthermore, to better understand the function of these ornaments, future work should examine how these colour patches appear to a female in relation to natural light conditions and the male's movements during display.

\section{Acknowledgements}

We would like to thank the Field Museum of Natural History (Chicago, IL, USA) for providing the feather specimens, and C. Eliason, D. Fecheyr-Lippens, B. Hsiung, N. Justyn, R. Maia, A. Nallapaneni, J. Peteya and M. Xiao for discussions or comments on the manuscript.

\section{Competing interests}

The authors declare no competing or financial interests. 


\section{Author contributions}

L.D.A. and M.D.S. conceived the study; B.I. and L.D.A. collected the data; B.I. analysed the data; and all authors contributed to writing.

\section{Funding}

This study was funded by grants from the Air Force Office of Scientific Research (FA9550-13-1-0222), the National Science Foundation (EAR-1251895) and the Human Frontier Science Program (RGY-0083) to M.D.S.

\section{Data availability}

Data available from the Dryad Digital Repository: http://dx.doi.org/10.5061/dryad. $2836 r$

\section{Supplementary information}

Supplementary information available online at

http://jeb.biologists.org/lookup/suppl/doi:10.1242/jeb.137182//DC1

\section{References}

Aguirre, C. I., Reguera, E. and Stein, A. (2010). Tunable colors in opals and inverse opal photonic crystals. Adv. Funct. Mater. 20, 2565-2578.

Andersson, M. (1994). Sexual Selection. Princeton, NJ: Princeton Univ. Press.

Bagnara, J. T., Fernandez, P. J. and Fujii, R. (2007). On the blue coloration of vertebrates. Pigment Cell Res. 20, 14-26.

Brink, D. and Van Der Berg, N. (2004). Structural colours from the feathers of the bird Bostrychia hagedash. J. Phys. D Appl. Phys. 37, 813-818.

Chen, I.-P., Stuart-Fox, D., Hugall, A. F. and Symonds, M. R. E. (2012). Sexual selection and the evolution of complex color patterns in dragon lizards. Evolution 66, 3605-3614.

Dakin, R. and Montgomerie, R. (2013). Eye for an eyespot: how iridescent plumage ocelli influence peacock mating success. Behav. Ecol. 24, 1048-1057.

D'Alba, L., Kieffer, L. and Shawkey, M. D. (2012). Relative contributions of pigments and biophotonic nanostructures to natural color production: a case study in budgerigar (Melopsittacus undulatus) feathers. J. Exp. Biol. 215, 1272-1277.

Doucet, S. M. and Meadows, M. G. (2009). Iridescence: a functional perspective. J. R. Soc. Interface 6, S115-S132.

Doucet, S. M., Mennill, D. J. and Hill, G. E. (2007). The evolution of signal design in manakin plumage ornaments. Am. Nat. 169, S62-S80.

Durães, R. (2009). Lek structure and male display repertoire of blue-crowned manakins in eastern Ecuador. Condor 111, 453-461.

Dyck, J. (1979). Winter plumage of the rock ptarmigan: structure of the air-filled barbules and function of the white colour. Dansk Orn. Foren. Tidsskr 73, 41-58.

Dyck, J. (1987). Structure and light reflection of green feathers of fruit doves (Ptilinopus spp.) and an imperial pigeon (Ducula concinna). Biol. Skr., 30, 1-43.

Echlin, P. (2011). Handbook of Sample Preparation for Scanning Electron Microscopy and X-ray Microanalysis. Cambridge, UK: Springer Science \& Business Media.

Eliason, C. M., Bitton, P.-P. and Shawkey, M. D. (2013). How hollow melanosomes affect iridescent colour production in birds. Proc. R. Soc. B Biol. Sci. 280 20131505

Endler, J. A. (1992). Signals, signal conditions, and the direction of evolution. Am Nat. 139, S125-S153.

Endler, J. A. and Thery, M. (1996). Interacting effects of lek placement, display behavior, ambient light, and color patterns in three neotropical forest-dwelling birds. Am. Nat. 148, 421-452.

Girard, M. B. and Endler, J. A. (2014). Peacock spiders. Curr. Biol. 24, R588-R590

Greenewalt, C. H., Brandt, W. and Friel, D. D. (1960). The iridescent colors of hummingbird feathers. Proc. Am. Philos. Soc., 104, 249-253.

Hanrahan, P. and Krueger, W. (1993). Reflection from layered surfaces due to subsurface scattering. In Proceedings of the 20th Annual Conference on Computer Graphics and Interactive Techniques, Anaheim, CA, USA, 26 August 1993, pp. 165-174. New York: ACM.

Hill, G. E. (2006). Female mate choice for ornamental coloration. In Bird Coloration Function and Evolution (ed. G. E. Hill and K. J. McGraw), pp. 137-200. Cambridge MA: Harvard University Press.

Igic, B., Fecheyr-Lippens, D., Xiao, M., Chan, A., Hanley, D., Brennan, P. R. L. Grim, T., Waterhouse, G. I. N., Hauber, M. E. and Shawkey, M. D. (2015). A nanostructural basis for gloss of avian eggshells. J. R. Soc. Interface 12 20141210

Kemp, D. J., Herberstein, M. E., Fleishman, L. J., Endler, J. A., Bennett, A. T. D. Dyer, A. G., Hart, N. S., Marshall, J. and Whiting, M. J. (2015). An integrative framework for the appraisal of coloration in nature. Am. Nat. 185, 705-724.

Kinoshita, S. (2008). Structural Colors in the Realm of Nature. Singapore: World Scientific.

Kirkpatrick, M. and Ryan, M. J. (1991). The evolution of mating preferences and the paradox of the lek. Nature 350, 33-38.

Kirwan, G. M. and Green, G. (2011). Cotingas and Manakins. Princeton, NJ: Princeton University Press.
Kodric-Brown, A. (1985). Female preference and sexual selection for male coloration in the guppy (Poecilia reticulata). Behav. Ecol. Sociobiol. 17, 199-205 Kraemer, A. C., Serb, J. M. and Adams, D. C. (2015). Batesian mimics influence the evolution of conspicuousness in an aposematic salamander. J. Evol. Biol. 28 1016-1023.

Leertouwer, H. L., Wilts, B. D. and Stavenga, D. G. (2011). Refractive index and dispersion of butterfly chitin and bird keratin measured by polarizing interference microscopy. Opt. Express 19, 24061.

Lukianchuk, K. C. and Doucet, S. (2014). Cooperative courtship display in longtailed manakins Chiroxiphia linearis: predictors of courtship success revealed through full characterization of display. J. Ornithol. 155, 729-743.

Magkiriadou, S., Park, J.-G., Kim, Y.-S. and Manoharan, V. N. (2014). Absence of red structural color in photonic glasses, bird feathers, and certain beetles. Phys. Rev. E 90, 062302.

Maia, R., D'Alba, L. and Shawkey, M. D. (2011). What makes a feather shine? A nanostructural basis for glossy black colours in feathers. Proc. R. Soc. B Biol. Sci. 278, 1973-1980.

Marchetti, K. (1993). Dark habitats and bright birds illustrate the role of the environment in species divergence. Nature 362, 149-152.

Meng, S. and Kaxiras, E. (2008). Theoretical models of eumelanin protomolecules and their optical properties. Biophys. J. 94, 2095-2105.

Noh, H., Liew, S. F., Saranathan, V., Mochrie, S. G. J., Prum, R. O., Dufresne E. R. and Cao, H. (2010a). How noniridescent colors are generated by quasiordered structures of bird feathers. Adv. Mater. 22, 2871-2880.

Noh, H., Liew, S. F., Saranathan, V., Prum, R. O., Mochrie, S. G. J., Dufresne, E. R. and Cao, H. (2010b). Double scattering of light from biophotonic nanostructures with short-range order. Opt. Express 18, 11942-11948.

OhIson, J. I., Fjeldså, J. and Ericson, P. G. P. (2013). Molecular phylogeny of the manakins (Aves: Passeriformes: Pipridae), with a new classification and the description of a new genus. Mol. Phylogenet. Evol. 69, 796-804.

Ohtsuka, Y., Seki, T. and Takeoka, Y. (2015). Thermally tunable hydrogels displaying angle-independent structural colors. Angew. Chem. Int. Ed. 127, 15588-15593.

Osorio, D. and Ham, A. (2002). Spectral reflectance and directional properties of structural coloration in bird plumage. J. Exp. Biol. 205, 2017-2027.

Osorio, D. and Vorobyev, M. (2005). Photoreceptor sectral sensitivities in terrestrial animals: adaptations for luminance and colour vision. Proc. R. Soc. $B$ Biol. Sci. 272, 1745-1752.

Price, T., Schluter, D. and Heckman, N. E. (1993). Sexual selection when the female directly benefits. Biol. J. Linn. Soc. 48, 187-211.

Prum, R. O. (1990). Phylogenetic analysis of the evolution of display behavior in the Neotropical manakins (Aves: Pipridae). Ethology 84, 202-231.

Prum, R. O. (1998). Sexual selection and the evolution of mechanical sound production in manakins (Aves: Pipridae). Anim. Behav. 55, 977-994.

Prum, R. (2006). Anatomy, physics, and evolution of structural colors. In Bird Coloration: Mechanisms and Measurements, Vol. 1 (ed. G. E. Hill and K. J. McGraw), pp. 295-353. Cambridge, MA: Harvard University Press.

Pryke, S. R. and Griffith, S. C. (2009). Postzygotic genetic incompatibility between sympatric color morphs. Evolution 63, 793-798.

Rêgo, P. S., Araripe, J., Marceliano, M. L. V., Sampaio, I. and Schneider, H. (2007). Phylogenetic analyses of the genera Pipra, Lepidothrix and Dixiphia (Pipridae, Passeriformes) using partial cytochrome b and 16S mtDNA genes. Zool. Scr. 36, 565-575.

Ribeiro, R. D., McCormack, J. E., Álvarez, H. G., Carrasco, L., Grether, G. F. Mena-Olmedo, P., Sedano, R., Smith, T. B. and Karubian, J. (2015). Loss of sexual dimorphism is associated with loss of lekking behavior in the green manakin Xenopipo holochora. J. Avian Biol. 46, 307-314

Ruxton, G. D., Sherratt, T. N. and Speed, M. P. (2004). Avoiding Attack: The Evolutionary Ecology of Crypsis, Warning Signals, and Mimicry. New York, NY: Oxford University Press.

Saba, M., Wilts, B. D., Hielscher, J. and Schröder-Turk, G. E. (2014). Absence of circular polarisation in reflections of butterfly wing scales with chiral gyroid structure. Materials Today Proceedings 1 (Suppl), 193-208.

Saranathan, V., Forster, J. D., Noh, H., Liew, S.-F., Mochrie, S. G. J., Cao, H. Dufresne, E. R. and Prum, R. O. (2012). Structure and optical function of amorphous photonic nanostructures from avian feather barbs: a comparative small angle X-ray scattering (SAXS) analysis of 230 bird species. J. R. Soc Interface 9, 2563-2580.

Seago, A. E., Brady, P., Vigneron, J.-P. and Schultz, T. D. (2009). Gold bugs and beyond: a review of iridescence and structural colour mechanisms in beetles (Coleoptera). J. R. Soc. Interface 6, S165-S184.

Setchell, J. M. and Jean Wickings, E. (2005). Dominance, status signals and coloration in male mandrills (Mandrillus sphinx). Ethology 111, 25-50.

Shawkey, M. D. and Hill, G. E. (2005). Carotenoids need structural colours to shine Biol. Lett. 1, 121-124.

Shawkey, M. D. and Hill, G. E. (2006). Significance of a basal melanin layer to production of non-iridescent structural plumage color: evidence from an amelanotic Steller's jay (Cyanocitta stelleri). J. Exp. Biol. 209, 1245-1250. 
Shawkey, M. D., Estes, A. M., Siefferman, L. M. and Hill, G. E. (2003). Nanostructure predicts intraspecific variation in ultraviolet-blue plumage colour. Proc. R. Soc. B Biol. Sci. 270, 1455-1460.

Shawkey, M. D., Saranathan, V., Pálsdóttir, H., Crum, J., Ellisman, M. H., Auer, M. and Prum, R. O. (2009). Electron tomography, three-dimensional Fourier analysis and colour prediction of a three-dimensional amorphous biophotonic nanostructure. J. R. Soc. Interface 6, S213-S220.

Shi, N. N., Tsai, C.-C., Camino, F., Bernard, G. D., Yu, N. and Wehner, R. (2015). Keeping cool: enhanced optical reflection and radiative heat dissipation in Saharan silver ants. Science 349, 298-301.

Smart, T., Lomas, H., Massignani, M., Flores-Merino, M. V., Perez, L. R. and Battaglia, G. (2008). Block copolymer nanostructures. Nano Today 3, 38-46.

Stavenga, D. G., Leertouwer, H. L., Marshall, N. J. and Osorio, D. (2011a). Dramatic colour changes in a bird of paradise caused by uniquely structured breast feather barbules. Proc. R. Soc. B Biol. Sci. 278, 2098-2104.

Stavenga, D. G., Tinbergen, J., Leertouwer, H. L. and Wilts, B. D. (2011b). Kingfisher feathers - colouration by pigments, spongy nanostructures and thin films. J. Exp. Biol. 214, 3960-3967.

Stavenga, D. G., Leertouwer, H. L., Osorio, D. C. and Wilts, B. D. (2015). High refractive index of melanin in shiny occipital feathers of a bird of paradise. Light Sci. Appl. 4, e243.

Stuart-Fox, D. and Moussalli, A. (2008). Selection for social signalling drives the evolution of chameleon colour change. PLOS Biol. 6, e25.

Takeoka, Y., Yoshioka, S., Takano, A., Arai, S., Nueangnoraj, K., Nishihara, H., Teshima, M., Ohtsuka, Y. and Seki, T. (2013). Production of colored pigments with amorphous arrays of black and white colloidal particles. Angew. Chem. Int. Ed. 52, 7261-7265.
Uy, J. A. C. and Endler, J. A. (2004). Modification of the visual background increases the conspicuousness of golden-collared manakin displays. Behav. Ecol. 15, 1003-1010.

Vukusic, P. and Sambles, J. R. (2003). Photonic structures in biology. Nature 424, 852-855.

Vukusic, P., Hallam, B. and Noyes, J. (2007). Brilliant whiteness in ultrathin beetle scales. Science $315,348$.

Welch, V. and Vigneron, J.-P. (2007). Beyond butterflies-the diversity of biological photonic crystals. Opt. Quant. Electron. 39, 295-303.

Wilts, B. D., Michielsen, K., De Raedt, H. and Stavenga, D. G. (2014). Sparkling feather reflections of a bird-of-paradise explained by finite-difference time-domain modeling. Proc. Natl. Acad. Sci. USA 111, 4363-4368.

Wilts, B. D., Matsushita, A., Arikawa, K. and Stavenga, D. G. (2015). Spectrally tuned structural and pigmentary coloration of birdwing butterfly wing scales. J. R. Soc. Interface 12, 20150717.

Xiao, M., Dhinojwala, A. and Shawkey, M. (2014). Nanostructural basis of rainbowlike iridescence in common bronzewing Phaps chalcoptera feathers. Opt. Express 22, $14625-14636$.

Xiao, M., Li, Y., Allen, M. C., Deheyn, D. D., Yue, X., Zhao, J., Gianneschi, N. C. Shawkey, M. D. and Dhinojwala, A. (2015). Bio-inspired structural colors produced via self-assembly of synthetic melanin nanoparticles. ACS Nano 9, 5454-5460.

Yoshioka, S. and Kinoshita, S. (2002). Effect of macroscopic structure in iridescent color of the peacock feathers. Forma 17, 169-181.

Young, C. M., Cain, K. E., Svedin, N., Backwell, P. R. Y. and Pryke, S. R. (2016). The role of pigment based plumage traits in resolving conflicts. J. Avian Biol. 47, 167-175.

Zhang, Y., Dong, B., Chen, A., Liu, X., Shi, L. and Zi, J. (2015). Using cuttlefish ink as an additive to produce non-iridescent structural colors of high color visibility. Adv. Mater. 27, 4719-4724. 